\title{
Personal Health Practices and Patient Counseling of German Physicians in Private Practice
}

\author{
Edgar Voltmer, ${ }^{1}$ Erica Frank, ${ }^{2}$ and Claudia Spahn ${ }^{3}$ \\ ${ }^{1}$ Department of Health and Behavioral Sciences, Friedensau Adventist University, An der Ihle 19, 39291 Friedensau, Germany \\ ${ }^{2}$ Faculty of Medicine, University of British Columbia, 2206 East Mall, Vancouver, BC, Canada V6T $1 Z 3$ \\ ${ }^{3}$ Freiburg Institute for Musicians' Medicine, Medical School of University of Freiburg, Breisacher Straße 60, \\ 79106 Freiburg, Germany
}

Correspondence should be addressed to Edgar Voltmer; edgar.voltmer@thh-friedensau.de

Received 14 May 2013; Accepted 10 July 2013

Academic Editors: D. Mandal and J. Peters

Copyright (C) 2013 Edgar Voltmer et al. This is an open access article distributed under the Creative Commons Attribution License, which permits unrestricted use, distribution, and reproduction in any medium, provided the original work is properly cited.

\begin{abstract}
We examined physicians' personal health behaviors and the influence on their patient counseling practices in a representative sample $(N=414)$ of physicians in private practice in Schleswig-Holstein, Germany. Physicians reported significantly better physical but poorer mental health compared to the general population (GP; $P>0.01)$. The majority presented with normal weight $(47.9 \%$ male, $73.1 \%$ female physicians versus $24.5 / 41.0 \%$ GP) or overweight ( $47.5 \%$ male, $20.0 \%$ female versus $52.9 / 35.6 \%$ GP). Frequency of exercise and fruit and vegetable consumption was higher than in the GP. About 70\% drank coffee or tea more than once a day, but only $13.2 \%$ of female and $21.8 \%$ of male physicians were current smokers (GP 20.1/30.5\%). More than half (56.1\%) usually or always counseled a typical patient on exercise versus nutrition (47.0\%), weight (45.8\%), smoking (39.9\%), and alcohol (30.0\%). Doctors with better personal exercise, nutrition, smoking, and alcohol behaviors counseled their patients significantly more often on related topics. Despite better physical health and health behaviors in these German doctors compared to the GP, there is room for improvement (smoking, overweight), which could be expected to positively influence the counseling practice and impact of doctors' role modeling on patients.
\end{abstract}

\section{Introduction}

Chronic, lifestyle-related diseases challenge health care systems worldwide with cardiovascular disease, chronic pulmonary disease, diabetes, and cancer accounting for about two-thirds of global mortality [1]. Lifestyle choices are critical for the prevention of these diseases [2]: WHO reports that the four leading risk factors for noncommunicable diseases are tobacco use, unhealthy diet, insufficient physical activity, and the harmful use of alcohol. Globally, tobacco causes almost six million deaths annually and alcohol 2.3 million. Insufficient exercise increases all-cause mortality 20 to $30 \%$, and fruit and vegetable consumption is important to prevent obesity, cardiovascular disease, and gastrointestinal cancers [1].

For most patients in western societies, physicians in private practice are their first contact regarding their personal health practices. Studies have shown the importance of doctors' recommendations for their patients' practices [3]. It has also been shown in North American studies that physicians have healthier habits than the general population and that doctors with the healthiest habits are more likely to counsel their patients about healthy lifestyle practices $[4,5]$. In addition, physicians with healthier behaviors, who discuss it with their patients, are more believable and motivating regarding prevention $[6,7]$. However, only about $16 \%$ of patient visits in US primary care included counseling on smoking, exercise, or diet [8].

In addition to the benefits for patients, healthy lifestyle practices for doctors may be important to prevent job-related stress and impairment for doctors themselves. Heavy workload, high responsibility, constant contact with ill and emotionally burdened people, and increased bureaucratization and administrative duties add to physicians' work-related stress and may lead to impairment and burnout [9-12]. 
Despite these multiple reasons to examine physician health, studies about personal healthy life style and counseling practices in Germany are limited. The aim of the present study was to examine health-related lifestyle practices of a representative sample of German physicians in private practice in Schleswig-Holstein and the correlation to their counseling practice. We hypothesized that (a) physicians have better personal health behaviors than the general population and that (b) physicians with better personal health behaviors counsel their patients more frequently than those with poorer health behaviors.

\section{Materials and Methods}

2.1. Sample Description. For this study we used data from the second wave (T2) of a longitudinal study. Initially a stratified (medical specialty), random sample of physicians was drawn from the Medical Association of Schleswig-Holstein. From a population of 3935 physicians (more than a third of all physicians in Schleswig-Holstein) [13], a sample of 900 was randomly selected. In 2010 at T2, 770 participants were still active and were included in the survey. Reminders to complete the survey were sent after four and eight weeks. To ensure anonymity, a random bar code was used to identify nonresponders. The study was approved by the Ethical Committee of the Medical Faculty of the University of Freiburg in a minimal risk review.

2.2. Measures. As a general measure for the quality of life we used the SF-12, developed from the original SF-36 Health Survey (http://www.sf-36.org/tools/sf36.shtml). The instrument is a self-report of subjective health and assesses physical functioning, role limitations due to physical and emotional health problems, freedom from bodily pain, general health perception, vitality, social functioning, and mental health. A summary score of physical and mental health can be calculated from these eight dimensions that account for more than $90 \%$ of the variance of the SF-36 results $[14,15]$.

For the evaluation of physicians' health-related lifestyle practices we used a set of items addressing exercise frequency, beverage consumption, fruit and vegetable consumption, and smoking. To compare these with the general population and other physician samples, most items were taken from the German national health survey or other international surveys of physicians $[16,17]$. Items were coded on a five- or seven-point Likert scale with $1=$ regularly/more than once a day to 5 or $7=<1$ time/week or never). Hours of sleep were queried directly. Items on personal preventive measures and clinical prevention counseling practice were taken from two large North American surveys, which took their personal prevention queries from Canadian (CCHS) and US (BRFSS) national surveys $[16,18]$. Clinical preventive measures included physical examination, blood pressure measurement, breast and testicular examination, influenza vaccination, measurement of cholesterol, Hemoccult test, mammography, and Papanicolaou smear (seven point-Likert scale $1=$ at least once a year to $7=$ never). In addition physicians were asked if they had a personal doctor (yes/no) and if they work when ill $(1=$ often to $4=$ never $)$. Regarding their counseling practice, physicians were asked how often they counseled a typical patient on nutrition, exercise, weight, smoking cessation, and alcohol or ordered a cholesterol test or a mammogram $(1=$ never/seldom, 2 = sometimes, and $3=$ usually/always).

2.3. Statistical Analysis. Data analyses were conducted with SPSS for windows Version 15.0 (SPSS Inc., Chicago, IL, USA). We report univariate statistics as means and standard deviations for continuous variables and percentages for categorical variables. For categorical variables, data were analyzed using $\chi^{2}$-tests. For continuous variables, data were analyzed using two tailed $t$-tests and analysis of variance in a general linear model (including adjustment for multiple testing). We calculated the mean of the two items on nutritional behavior and labelled physicians with a mean of $<2.4$ of combined fruit and vegetable consumption as high frequency consumption and the others as low. For alcohol consumption we used the median split of the mean scores of the three items.

\section{Results}

3.1. Basic Demographic and Employment Characteristics. The response rate was $53.8 \%$ (414/770). There were no significant differences in age and specialty between responders and nonresponders, but a higher percentage of female physicians (61.3\% versus $38.7 \%)$ participated $(P<0.01)$. The sample consists of $60 \%$ male and $40 \%$ female physicians. Consistent with the stratification, $35.5 \%$ were general practitioners and medical specialists and $29.0 \%$ surgical specialists. The mean age was 53.1 (SD 7.3) years.

3.2. Physicians' Personal Health Behaviors. Compared to reference samples of the general population, both male and female physicians had better physical but poorer mental health (SF-12; Table 1). Male physicians had significantly higher scores in physical health than their female colleagues but did not differ significantly in mental health. Very few physicians were underweight or obese (Table 1). The majority presented with normal (58\%) or overweight (36.6\%). A significantly higher proportion of female physicians had normal weight (73.1\% female versus $47.9 \%$ male), and a lower proportion were overweight (20\% female versus $47.5 \%$ male).

In total about $40 \%$ of physicians exercised two hours or more per week, about $50 \%$ exercised $>0$ to $<2 \mathrm{~h} /$ week, and $11 \%$ never exercised (Table 2 ). The majority of physicians reported $6 \mathrm{~h}(38 \%)$ or $7 \mathrm{~h}(40 \%)$ sleep per night (mean male $6.5 \mathrm{~h}, \mathrm{SD}$ 0.8 , female 6.7 h, SD 0.9 ; n.s.).

Table 3 summarizes these physicians' eating, drinking, and smoking habits. Female physicians had a significantly more frequent intake of vegetables and fruit than their male colleagues. More than $90 \%$ of male and female physicians drank coffee or black tea at least once a day and about $70 \%$ more than once a day. More than $90 \%$ of male and female physicians consumed water (more than) once a day. A significantly smaller proportion of female physicians were current smoker (13.2\% versus male $21.8 \%$ ) and $55.9 \%$ of them had never smoked (male $40.4 \%$ ). 
TABLE 1: Health indices of German physicians in private practice.

\begin{tabular}{|c|c|c|c|c|}
\hline & Men $(\% ; n=243)$ & Women $(\% ; n=161)$ & Total $(\% ; n=404)$ & $P_{\mathrm{mf}}$ \\
\hline Body mass index (BMI) & & & & $<0.001$ \\
\hline$<18.5 \mathrm{~kg} / \mathrm{m}^{2}$ & 0.4 & 2.5 & 1.2 & \\
\hline$\geq 18.5$ to $\leq 25$ & 47.9 & 73.1 & 58.0 & \\
\hline$>25$ to $\leq 30$ & 47.5 & 20.0 & 36.6 & \\
\hline$>30$ & 4.1 & 4.4 & 4.2 & \\
\hline $\begin{array}{l}\text { Blood pressure }(B P) \\
\left(n_{\text {male }}=163, n_{\text {female }}=124\right)\end{array}$ & & & & 0.573 \\
\hline Syst $\leq 139$, diast $\leq 89$ & 92.0 & 94.4 & 93.0 & \\
\hline Syst $140-159$, diast $90-99$ & 7.4 & 5.6 & 6.6 & \\
\hline$\geq 160 / 100$ & 0.6 & 0.0 & 0.3 & \\
\hline $\begin{array}{l}\text { Physical health (SF-12) } \\
\text { Reference GP }\end{array}$ & $\begin{array}{c}\text { M } 52.0(\text { SD 6.5) } \\
\text { M } 50.2(\text { SD 8.7) }\end{array}$ & $\begin{array}{c}\text { M } 50.1(\text { SD 7.6) } \\
\text { M } 47.9 \text { (SD 9.7) }^{* *}\end{array}$ & $\begin{array}{c}\text { M } 51.3(\text { SD 6.9) } \\
\text { M } 49.0(\text { SD 9.4) }\end{array}$ & 0.009 \\
\hline $\begin{array}{l}\text { Mental health (SF-12) } \\
\text { Reference GP }\end{array}$ & $\begin{array}{c}\text { M } 48.3(\text { SD 9.7) } \\
\text { M } 53.3(\text { SD 7.6) }\end{array}$ & $\begin{array}{l}\text { M } 47.7(\text { SD 10.3)** } \\
\text { M } 51.3(\text { SD 8.4) }\end{array}$ & $\begin{array}{c}\text { M } 48.1(\text { SD 9.9) } \\
\text { M } 52.2(\text { SD 8.1) }\end{array}$ & 0.587 \\
\hline
\end{tabular}

${ }^{* *} P<0.01$ to reference

m: male, f: female

M: mean, SD: standard deviation.

TABLE 2: Exercise and sleep habits of German physicians in private practice.

\begin{tabular}{lcccc}
\hline & $\begin{array}{c}\text { Male (\%) } \\
(n=229-242)\end{array}$ & $\begin{array}{c}\text { Female (\%) } \\
(n=153-160)\end{array}$ & $\begin{array}{c}\text { Total (\%) } \\
(n=382-402)\end{array}$ & $P_{\mathrm{mf}}$ \\
\hline Exercise & & & & 0.132 \\
$>4 \mathrm{~h} /$ week & 14.0 & 15.6 & 14.7 & \\
2-4 h/week & 25.2 & 25.0 & 25.1 & \\
1-2 h/week & 24.0 & 28.8 & 25.9 & \\
$<1 \mathrm{~h} /$ week & 27.3 & 16.9 & 23.1 & \\
No exercise & 9.5 & 13.8 & 11.2 & \\
\hline Sleep & & & & 0.092 \\
$<6 \mathrm{~h}$ & 7.8 & 8.5 & 8.2 & \\
$6 \mathrm{~h}$ & 40.6 & 34.0 & 38.0 & \\
$7 \mathrm{~h}$ & 41.0 & 38.6 & 40.1 & \\
$8 \mathrm{~h}$ & 10.5 & 17.0 & 13.1 & \\
$9 \mathrm{~h}$ & 0.0 & 2.0 & 0.8 & \\
\hline
\end{tabular}

m: male, f: female.

More than $50 \%$ of male and female physicians had a physical examination in the last two years (Table 4). However, for almost $30 \%$ of male and $36 \%$ of female physicians it was more than 4 years ago or never. The gender differences here and in blood pressure checks $(66 \%<1 /$ year) were not significant.

While $75.6 \%$ of female physicians had a breast examination in the last two years by a clinician, only $30.8 \%$ of male physicians had a testicular examination. More than $60 \%$ of male and female physicians had an influenza vaccination or a cholesterol measurement in the last two years, but about $29 \%$ (vaccination) or $14 \%$ (cholesterol) never had one. Almost half of the male and female physicians never had a Hemoccult test $(42.2 \%$ male and $30.0 \%$ female physicians aged $>50$ never had one and $19.7 \%$ of male and $21.1 \%$ female physicians $>50$ years had one within the last year). Gender differences in vaccination, cholesterol, and Hemoccult measurement rates were not significant. Sixty-three percent of all female physicians had a mammography within the last two years and $68 \%$ of those within fifty years and older. However, in this group $11 \%$ never had a mammography (not shown). More than $70 \%$ of female physicians had a Papanicolaou smear within the last two years (Table 4 ).

3.3. Physicians' Counseling Practices and Their Relationship to Physicians' Personal Health Behaviors. More than half of all physicians (56.1\%) usually/always counseled a typical patient on exercise, $47.0 \%$ on nutrition, $45.8 \%$ about weight, $39.9 \%$ on smoking, $30.0 \%$ about alcohol, $28.1 \%$ on cholesterol, and $27.6 \%$ about mammography (Table 5). In all topics except mammography general practitioners reported significantly more frequently that they counseled usually/always than did medical or surgical specialists. Except for counseling on alcohol and ordering mammography there were no significant gender differences in counseling practice. In both of these topics, female doctors reported more often that they usually/always counseled a typical patient.

Physicians who exercised, consumed fruit and vegetables more frequently, did not smoke, and drank less alcohol counseled patients significantly more often about the related topics (Table 6). Descriptively those doctors with a normal body weight reported more frequently counseling usually/always on nutrition, weight, and exercise, but these correlations were not significant.

\section{Discussion}

This study examined quality of life and personal health behaviors of German physicians in private practice and, to our knowledge for the first time, the relation to their counseling practices. 
TABLE 3: German physicians' eating, drinking, and smoking habits.

\begin{tabular}{|c|c|c|c|c|}
\hline & $\begin{array}{c}\text { Male }(\%) \\
(n=223-242)\end{array}$ & $\begin{array}{c}\text { Female (\%) } \\
(n=150-159)\end{array}$ & $\begin{array}{c}\text { Total }(\%) \\
(n=373-401)\end{array}$ & $P_{\mathrm{mf}}$ \\
\hline \multicolumn{5}{|l|}{ Diet } \\
\hline Salad, raw vegetables & & & & 0.009 \\
\hline (More than) once a day & 58.0 & 70.7 & 63.0 & \\
\hline (More than) once a week & 39.4 & 26.0 & 34.0 & \\
\hline$<$ once a week & 2.7 & 3.3 & 2.9 & \\
\hline Fresh fruit & & & & 0.001 \\
\hline (More than) once a day & 63.7 & 82.7 & 71.3 & \\
\hline (More than) once a week & 31.8 & 15.3 & 25.2 & \\
\hline$<$ once a week & 4.5 & 2.0 & 3.5 & \\
\hline \multicolumn{5}{|l|}{ Drinking } \\
\hline Coffee/black tea & & & & 0.471 \\
\hline (More than) once a day & 93.4 & 90.6 & 92.3 & \\
\hline (More than) once a week & 3.7 & 3.1 & 3.4 & \\
\hline (More than) once a month & 0.8 & 1.9 & 1.2 & \\
\hline (Almost) never & 2.1 & 4.4 & 3.0 & \\
\hline Beer & & & & 0.000 \\
\hline (More than) once a day & 17.9 & 1.9 & 11.6 & \\
\hline (More than) once a week & 37.9 & 10.8 & 27.1 & \\
\hline (More than) once a month & 22.5 & 29.1 & 25.1 & \\
\hline (Almost) never & 21.7 & 58.2 & 36.2 & \\
\hline Wine & & & & 0.259 \\
\hline (More than) once a day & 19.6 & 11.3 & 16.3 & \\
\hline (More than) once a week & 50.8 & 52.2 & 51.4 & \\
\hline (More than) once a month & 20.4 & 27.7 & 23.3 & \\
\hline (Almost) never & 9.2 & 8.8 & 9.0 & \\
\hline Hard liquor & & & & 0.000 \\
\hline (More than) once a day & 1.2 & 0.0 & 0.8 & \\
\hline (More than) once a week & 12.4 & 4.4 & 9.3 & \\
\hline (More than) once a month & 40.2 & 28.5 & 35.6 & \\
\hline (Almost) never & 46.1 & 67.1 & 54.4 & \\
\hline Fruit and vegetable juice & & & & 0.004 \\
\hline (More than) once a day & 58.1 & 39.2 & 50.6 & \\
\hline (More than) once a week & 27.4 & 32.3 & 29.3 & \\
\hline (More than) once a month & 9.5 & 15.8 & 12.0 & \\
\hline (Almost) never & 5.0 & 12.7 & 8.0 & \\
\hline Water & & & & 0.049 \\
\hline (More than) once a day & 92.1 & 92.4 & 92.2 & \\
\hline (More than) once a week & 5.8 & 7.0 & 6.3 & \\
\hline (More than) once a month & 1.7 & 0.0 & 1.0 & \\
\hline (Almost) never & 0.4 & 0.6 & 0.5 & \\
\hline \multicolumn{5}{|l|}{ Smoking } \\
\hline Smoker & 21.8 & 13.2 & 18.3 & 0.039 \\
\hline Former smoker & 37.9 & 30.3 & 34.7 & \\
\hline Never smoked & 40.4 & 55.9 & 46.7 & \\
\hline
\end{tabular}

$P_{\mathrm{m} \text { f }}$ describes statistical significance between $\mathrm{m}$ : male and f: female. 
TABLE 4: German physicians' personal clinical preventive measures.

\begin{tabular}{|c|c|c|c|c|}
\hline & $\begin{array}{c}\text { Men } \\
(\% ; n= \\
239-243)\end{array}$ & $\begin{array}{c}\text { Women } \\
(\% ; n= \\
159-161)\end{array}$ & $\begin{array}{c}\text { Total } \\
(\% ; n= \\
398-404)\end{array}$ & $P_{\mathrm{mf}}$ \\
\hline Physical checkup & & & & 0.346 \\
\hline$<1$ year & 32.9 & 32.9 & 32.9 & \\
\hline 1 to $<2$ years & 21.8 & 19.3 & 20.8 & \\
\hline 2 to $<3$ years & 8.6 & 8.1 & 8.4 & \\
\hline 3 to $<4$ years & 7.8 & 3.7 & 6.2 & \\
\hline 4 to $<5$ years & 5.3 & 10.6 & 7.4 & \\
\hline$\geq 5$ years & 14.8 & 16.8 & 15.6 & \\
\hline Never & 8.6 & 8.7 & 8.7 & \\
\hline Blood pressure check & & & & 0.103 \\
\hline$<1$ year & 63.1 & 70.8 & 66.2 & \\
\hline 1 to $<2$ years & 17.0 & 14.3 & 15.9 & \\
\hline 2 to $<3$ years & 6.2 & 4.3 & 5.5 & \\
\hline 3 to $<4$ years & 2.1 & 3.7 & 2.7 & \\
\hline 4 to $<5$ years & 2.1 & 3.1 & 2.5 & \\
\hline$\geq 5$ years & 5.4 & 3.7 & 4.7 & \\
\hline Never & 4.1 & 0.0 & 2.5 & \\
\hline $\begin{array}{l}\text { Breast or testicular } \\
\text { examination (by clinician) }\end{array}$ & & & & $>0.001$ \\
\hline$<1$ year & 19.6 & 56.9 & 34.5 & \\
\hline 1 to $<2$ years & 11.3 & 18.8 & 14.3 & \\
\hline 2 to $<3$ years & 10.4 & 10.6 & 10.5 & \\
\hline 3 to $<4$ years & 6.7 & 1.9 & 4.8 & \\
\hline 4 to $<5$ years & 3.3 & 3.1 & 3.3 & \\
\hline$\geq 5$ years & 12.1 & 5.6 & 9.5 & \\
\hline Never & 36.7 & 3.1 & 23.3 & \\
\hline Influenza vaccine & & & & 0.600 \\
\hline$<1$ year & 55.1 & 46.6 & 51.7 & \\
\hline 1 to $<2$ years & 11.5 & 14.9 & 12.9 & \\
\hline 2 to $<3$ years & 2.5 & 2.5 & 2.5 & \\
\hline 3 to $<4$ years & 1.2 & 1.2 & 1.2 & \\
\hline 4 to $<5$ years & 1.2 & 1.9 & 1.5 & \\
\hline$\geq 5$ years & 0.8 & 2.5 & 1.5 & \\
\hline Never & 27.6 & 30.4 & 28.7 & \\
\hline Cholesterol measurement & & & & 0.432 \\
\hline$<1$ year & 42.4 & 31.9 & 38.2 & \\
\hline 1 to $<2$ years & 21.8 & 23.1 & 22.3 & \\
\hline 2 to $<3$ years & 7.8 & 8.8 & 8.2 & \\
\hline 3 to $<4$ years & 5.8 & 5.6 & 5.7 & \\
\hline 4 to $<5$ years & 2.9 & 5.0 & 3.7 & \\
\hline$\geq 5$ years & 7.0 & 8.8 & 7.7 & \\
\hline Never & 12.3 & 16.9 & 14.1 & \\
\hline Hemoccult test & & & & 0.996 \\
\hline$<1$ year & 13.8 & 14.5 & 14.1 & \\
\hline 1 to $<2$ years & 13.0 & 13.2 & 13.1 & \\
\hline
\end{tabular}

TABLE 4: Continued.

\begin{tabular}{|c|c|c|c|c|}
\hline & $\begin{array}{c}\text { Men } \\
(\% ; n= \\
239-243)\end{array}$ & $\begin{array}{c}\text { Women } \\
(\% ; n= \\
159-161)\end{array}$ & $\begin{array}{c}\text { Total } \\
(\% ; n= \\
398-404)\end{array}$ & $P_{\mathrm{mf}}$ \\
\hline 2 to $<3$ years & 7.5 & 8.2 & 7.8 & \\
\hline 3 to $<4$ years & 5.0 & 5.7 & 5.3 & \\
\hline 4 to $<5$ years & 4.6 & 5.7 & 5.0 & \\
\hline$\geq 5$ years & 6.7 & 6.9 & 6.8 & \\
\hline Never & 49.4 & 45.9 & 48.0 & \\
\hline Mammogram & N/A & & & \\
\hline$<1$ year & & 40.7 & & \\
\hline 1 to $<2$ years & & 22.2 & & \\
\hline 2 to $<3$ years & & 9.3 & & \\
\hline 3 to $<4$ years & & 2.5 & & \\
\hline 4 to $<5$ years & & 2.5 & & \\
\hline$\geq 5$ years & & 3.7 & & \\
\hline Never & & 19.1 & & \\
\hline Papanicolaou smear & N/A & & & \\
\hline$<1$ year & & 50.0 & & \\
\hline 1 to $<2$ years & & 23.8 & & \\
\hline 2 to $<3$ years & & 6.9 & & \\
\hline 3 to $<4$ years & & 5.6 & & \\
\hline 4 to $<5$ years & & 4.4 & & \\
\hline$\geq 5$ years & & 6.3 & & \\
\hline Never & & 3.1 & & \\
\hline $\begin{array}{l}\text { Working when ill } \\
\text { (presenteeism) }\end{array}$ & & & & 0.158 \\
\hline Often & 11.7 & 17.3 & 13.9 & \\
\hline Sometimes & 27.5 & 32.7 & 29.6 & \\
\hline Seldom & 36.7 & 29.0 & 33.6 & \\
\hline Never & 24.2 & 21 & 22.9 & \\
\hline Personal doctor & & & & 1.000 \\
\hline Yes & 31.7 & 31.7 & 31.7 & \\
\hline No & 68.3 & 68.3 & 68.3 & \\
\hline
\end{tabular}

$P_{\mathrm{m} f}$ describes statistical significance between $\mathrm{m}$ : male and f: female.

4.1. Physicians' Personal Health Behaviors. Physicians reported significantly better physical health (SF-12) compared to the general population (GP) [19]. Consistent with this finding and our first hypothesis, physicians typically consumed fruit and vegetables and drank water more frequently than the general population, women did so to a significantly higher proportion than men [20]. Three-fourths of these physicians consumed water at least daily, and a much lower proportion than in the general population reported no water consumption ( $0.5 \%$ physicians versus $9 \%$ male GP, $5 \%$ female GP) [21].

Almost half (47.9\%) of male physicians and $73.1 \%$ of female physicians (versus $24.5 \%$ of German GP men and 41.0\% German GP women) [22] reported a normal bodyweight, and far fewer were obese $(4.1 \%$ of male physicians versus $22.5 \% \mathrm{GP}$ men and $4.4 \%$ of female physicians versus 
TABLE 5: Relationship between German physicians' gender and speciality and their related counseling habits in private practice.

\begin{tabular}{|c|c|c|c|c|c|c|c|c|}
\hline $\begin{array}{l}\text { Counsels a typical } \\
\text { patient on }\end{array}$ & $(\% ; n=373-401)$ & $\begin{array}{c}\text { Male } \\
(\% ; n= \\
226-243)\end{array}$ & $\begin{array}{c}\text { Female }(\% ; n= \\
147-158)\end{array}$ & $P_{\mathrm{mf}}$ & $\begin{array}{c}\mathrm{GP} \\
(\% ; n=139)\end{array}$ & $\begin{array}{c}\text { Medical } \\
(\% ; n=123)\end{array}$ & $\begin{array}{c}\text { Surgical } \\
(\% ; n=113)\end{array}$ & $P_{\text {Specialty }}$ \\
\hline Nutrition & & & & 0.269 & & & & 0.000 \\
\hline Never/rarely & 6.9 & 7.9 & 5.7 & & 2.8 & 7.6 & 11.2 & \\
\hline Sometimes & 46.1 & 47.9 & 42.0 & & 35.9 & 40.7 & 65.5 & \\
\hline Usually/always & 47.0 & 44.2 & 52.2 & & 61.4 & 51.7 & 23.3 & \\
\hline Exercise & & & & 0.228 & & & & 0.000 \\
\hline Never/rarely & 4.2 & 4.5 & 3.8 & & 2.8 & 3.4 & 6.8 & \\
\hline Sometimes & 39.7 & 42.8 & 34.8 & & 27.6 & 34.9 & 60.7 & \\
\hline Usually/always & 56.1 & 52.7 & 61.4 & & 69.7 & 61.6 & 32.5 & \\
\hline Weight & & & & 0.133 & & & & 0.000 \\
\hline Never/rarely & 4.7 & 3.3 & 7.0 & & 2.8 & 4.1 & 7.7 & \\
\hline Sometimes & 49.5 & 52.3 & 44.9 & & 40.7 & 42.5 & 69.2 & \\
\hline Usually/always & 45.8 & 44.4 & 48.1 & & 56.6 & 53.4 & 23.1 & \\
\hline Smoking & & & & 0.914 & & & & 0.000 \\
\hline Never/rarely & 15.5 & 15.8 & 14.3 & & 5.5 & 20.7 & 21.6 & \\
\hline Sometimes & 44.6 & 45.0 & 45.5 & & 38.6 & 40.7 & 56.9 & \\
\hline Usually/always & 39.9 & 39.2 & 40.3 & & 55.9 & 38.6 & 21.6 & \\
\hline Alcohol & & & & 0.013 & & & & 0.000 \\
\hline Never/rarely & 16.6 & 15.3 & 18.2 & & 4.1 & 17.0 & 31.6 & \\
\hline Sometimes & 53.3 & 59.5 & 44.8 & & 51.7 & 46.1 & 64.1 & \\
\hline Usually/always & 30.0 & 25.2 & 37.0 & & 44.1 & 36.9 & 4.3 & \\
\hline Cholesterol & & & & 0.928 & & & & 0.000 \\
\hline Never/rarely & 46.7 & 46.4 & 48.0 & & 8.4 & 59.7 & 79.1 & \\
\hline Sometimes & 25.3 & 25.3 & 23.6 & & 30.1 & 29.9 & 13.9 & \\
\hline Usually/always & 28.1 & 28.3 & 28.4 & & 61.5 & 10.4 & 7.0 & \\
\hline Mammogram & & & & 0.005 & & & & 0.000 \\
\hline Never/rarely & 51.6 & 57.5 & 42.2 & & 21.6 & 81.9 & 54.4 & \\
\hline Sometimes & 20.8 & 20.4 & 21.8 & & 36.0 & 13.4 & 10.5 & \\
\hline Usually/always & 27.6 & 22.1 & 36.1 & & 42.4 & 4.7 & 35.1 & \\
\hline
\end{tabular}

$P_{\mathrm{m} f}$ describes statistical significance between $\mathrm{m}$ : male and f: female.

23.3\% GP women). While the proportion of overweight female physicians also differed markedly from the GP $(20 \%$ versus $35.6 \%$ ) the differences were less prominent for male physicians (47.5\% male physicians versus $52.9 \%$ male GP). Compared to a Canadian sample a slightly higher proportion of German doctors had normal body weight ( $58 \%$ versus $54 \%$ ) and a lower proportion was obese (4\% versus $8 \%$ ) [16]. Given the high risk of overweight and obesity as risk factor for illness and mortality $[23,24]$, male physicians appear to be an important group for preventive measures. An obvious target for intervention may be to increase male physician's fruit and vegetable consumption to reduce overweight [25] and prevent illness [26].

The World Health Organization recommends at least 150 min of exercise with moderate intensity per week [27]. Preventive effects on various diseases and all-cause mortality have been described $[28,29]$. In our study, physicians exercised more regularly than the GP; $14.0 \%$ of male and $15.6 \%$ of female physicians exercised $>4$ hours/week versus $10.5 \%$ male and $5.1 \%$ of females in the GP [30]. About one-fourth of male and female physicians exercised two to four hours a week (versus $13.0 \%$ of males and $10.3 \%$ females in the GP). While about $40 \%$ of the physicians in our study performed around or above the WHO minimum, more than $60 \%$ did not.

Physicians were less likely to smoke than the GP (18.3\% versus $30 \%$ ), but still $21.8 \%$ of male physicians (versus $34 \%$ among male GP) and $13.2 \%$ of female physicians (versus $26 \%$ among female GP) were current smokers [20]. Consistent with these findings, Lampert reported from the German 2005 microcensus the smoking rate of $19.1 \%$ smokers among physicians [31]. However, this was a much higher percentage 
TABle 6: Physicians' personal health behaviors and their related counseling habits.

\begin{tabular}{|c|c|c|c|c|c|}
\hline Independent variables & Never/rarely \% & Sometimes \% & Usually/always \% & Total $n(\%)$ & $P$ \\
\hline Doctors' exercise habits versus their patient exercise counseling & & & & & 0.007 \\
\hline $2 \mathrm{~h}$ to $\geq 4 \mathrm{~h}$ & 2.4 & 32.1 & 65.5 & $165(40.5 \%)$ & \\
\hline$\leq 1-2 \mathrm{~h}$ & 6.1 & 42.6 & 51.3 & $197(48.4 \%)$ & \\
\hline Never & 2.2 & 55.6 & 42.2 & $45(11.1 \%)$ & \\
\hline Doctors' BMI versus doctors' counseling patients on nutrition & & & & & 0.816 \\
\hline$<18.5 \mathrm{~kg} / \mathrm{m}^{2}$ & 0.0 & 60.0 & 40.0 & $5(1.3)$ & \\
\hline$\geq 18.5$ to $\leq 25$ & 6.9 & 44.2 & 48.9 & $231(57.8)$ & \\
\hline$>25$ to $\leq 30$ & 8.2 & 47.6 & 44.2 & $147(36.8)$ & \\
\hline$>30$ & 0.0 & 52.9 & 47.1 & $17(4.3)$ & \\
\hline Doctors' BMI versus doctors' counseling patients on weight & & & & & 0.234 \\
\hline$<18.5 \mathrm{~kg} / \mathrm{m}^{2}$ & 0.0 & 100.0 & 0.0 & $5(1.2)$ & \\
\hline$\geq 18.5$ to $\leq 25$ & 4.7 & 46.4 & 48.9 & $233(58.0)$ & \\
\hline$>25$ to $\leq 30$ & 4.8 & 51.0 & 44.2 & $147(36.6)$ & \\
\hline$>30$ & 5.9 & 64.7 & 29.4 & $17(4.2)$ & \\
\hline Doctors' BMI versus doctors' counseling patients on exercise & & & & & 0.590 \\
\hline$<18.5 \mathrm{~kg} / \mathrm{m}^{2}$ & 0.0 & 60.0 & 40.0 & $5(1.2)$ & \\
\hline$\geq 18.5$ to $\leq 25$ & 3.4 & 40.3 & 56.2 & $233(58.0)$ & \\
\hline$>25$ to $\leq 30$ & 6.1 & 36.7 & 57.1 & $147(36.6)$ & \\
\hline$>30$ & 0.0 & 52.9 & 47.1 & $17(4.2)$ & \\
\hline Doctors' fruit and vegetable consumption and counseling on nutrition & & & & & 0.001 \\
\hline High & 4.8 & 41.0 & 54.2 & $227(59.6)$ & \\
\hline Low & 9.7 & 54.5 & 35.7 & $154(40.4)$ & \\
\hline Doctors' fruit and vegetable consumption and counseling on weight & & & & & 0.065 \\
\hline High & 3.9 & 45.6 & 50.4 & $228(59.7)$ & \\
\hline Low & 5.2 & 56.5 & 38.3 & $154(40.3)$ & \\
\hline Doctors' fruit and vegetable consumption and counseling on exercise & & & & & $<0.001$ \\
\hline High & 3.9 & 32.5 & 63.6 & $228(59.7)$ & \\
\hline Low & 4.5 & 51.9 & 43.5 & $154(40.3)$ & \\
\hline Doctors' smoking behavior and counseling on smoking & & & & & 0.012 \\
\hline Smoker & 22.4 & 53.7 & 23.9 & $67(17.8)$ & \\
\hline Nonsmoker & 13.6 & 44.0 & 42.4 & $309(82.2)$ & \\
\hline Doctors' alcohol consumption and counseling on alcohol & & & & & 0.047 \\
\hline Low (median split) & 18.7 & 47.2 & 34.2 & $193(48.3)$ & \\
\hline High (median split) & 15.0 & 59.4 & 25.6 & $207(51.8)$ & \\
\hline
\end{tabular}

than has been reported by US (4\%) [32-34] and Canadian physicians (3.3\%) [16] and Swiss primary care physicians (12\%) [35].

The majority of physicians reported receiving clinical preventive measures like physical checkup, blood pressure check, and influenza vaccination within the last two years. However, the proportion of those who failed to do so within the last 5 years or ever did so was not small, and two-thirds of these physicians reported that they had no regular personal doctor. This supports the findings of other physician and medical student studies, showing good but not exemplary screening habits and lack of personal doctors [16, 34, 36-38]. Physicians may be especially aware of the limitations of medical practice, fear loss of confidentiality and negative consequences of personal weakness or illness, and tend to self-diagnose and self-prescribe $[39,40]$. Doctors also tend to work despite being ill [41]. Compared to Canadian physicians (11\%) [16] a higher percentage of the German physicians (23\%) reported that they never work when ill, but $44 \%$ work when ill at least sometimes. Medical culture should better encourage physicians to take the time to rest to cure illness for their personal health and also to prevent contagion and be a role model for patients and employees [42, 43].

Differences of the large-scale Canadian Physician Health Study [16] were also seen with a higher frequency of influenza vaccination within the last year in Canadian physicians $(75 \%$ Canadian versus $52 \%$ German). Low influenza vaccination rates in German health care workers have been reported before $[44,45]$, but at least in physicians of this northern state of Germany rates appear to have increased. However, 29\% of German physicians (versus $9 \%$ of Canadian physicians) reported that they never have received this intervention 
(recommended annually by the German "Ständige Impfkommission (STIKO)" for health care professionals).

\subsection{Physicians' Counseling Practices and Correlations with} Their Personal Health Behaviors. Physicians' preventive advice can substantively improve patients' health behaviors [46-48], but this often-effective clinical practice is performed infrequently. Only about $16 \%$ of patient visits in US primary care included counseling on smoking, exercise, or diet [8], and only one-third of obese patients reported that this has been addressed by their physician [49]. In a study on fostering smoking cessation in private practice, only $42 \%$ of German patients reported that doctors have ever addressed their smoking behavior, and only $27 \%$ had received such advice in the past year [50].

In our study most of these physicians counseled their patients on nutrition, exercise, or weight at least sometimes, but there was a higher percentage of physicians who never counseled on smoking and alcohol. Given that smoking is the most important preventable health risk factor [51, 52], the proportion of male physicians $(22 \%)$ who were current smokers and the $16 \%$ who never counseled a typical patient on smoking would be particularly important targets for improvement.

The same was true for these German physicians' patient screening practices. After a long and controversial public and scientific discussion, a quality-assured mammography screening program was introduced in Germany in 2005. Women, aged 50 to 69 years, are invited every two years to a mammogram [53]. However, the debate continues about the actual effect on mortality reduction and about false positive/negative results and the overtreatment of small cancers [54-56]. Biesheuvel et al. [56] report that despite all public efforts the attendance rate is low (53\%). For them one reason might be the controversies in the ongoing discussion that might also be reflected in the high proportion of physicians that never order a mammography in our data. Consistent with prior literature [57] our findings demonstrate that women physicians were more likely than the female general population to participate-about two-thirds (63\%) of female physicians had a mammography (68\% age 50 and older) and to order a patient mammogram.

The higher prevention counseling frequency reported here of female physicians is supported by findings of US and Canadian studies [6,57-59]. While male physicians focus more on medical history taking and physical examination, female physicians counsel more frequently on preventive issues and psychosocial problems [57, 60]. Likewise, and consistent with our results, primary care physicians have been found to counsel more frequently on preventive issues than specialized colleagues [58].

The most important finding of our study was that (as hypothesized) physicians who exercised, were non-smokers, ate fruit and vegetables more frequently, and drank alcohol less frequently were significantly more likely to counsel their patients on these topics. This is consistent with the results in Canadian and US physicians who report a strong, consistent and positive relationship between personal and clinical prevention practices for smoking, drinking, alcohol, exercise, fruit and vegetable consumption, and BMI $[18,58$, $61]$.

4.3. Strength and Limitations. We examined a representative sample of physicians in private practice in one federal state of Germany, so our results may not be representative of all German physicians. Compared to other physician survey's response rates (41\% [16], 49\% [34], 31\% [62]) the response rate was good (54\%), particularly among the important and growing cohort of women physicians, though certainly still susceptible to a response bias. An adjustment for multiple testing was provided in the general linear model but not in the cross-tabulations. Since the results are based on self-reported data, more objective measures would be valuable.

\section{Conclusions}

Physicians in private practice in Schleswig-Holstein consistently reported better personal health behaviors than the general population, though some critical areas warrant attention, especially smoking and overweight in male physicians and screening practices in both genders. Counseling rates overall had considerable room for improvement (especially among surgeons), but those with better personal health behaviors counseled patients more frequently about various health issues than those with poorer personal health behaviors. Since doctors are important advisors and role models for their patients, health promotion for physicians in these areas should be fostered.

\section{Conflict of Interests}

The authors declare that there is no conflict of interests.

\section{Acknowledgments}

The authors kindly thank the medical association of Schleswig-Holstein for the generous support of the study. The authors also thank Dr. med. Thomas Kötter, University of Lübeck for the revision of the paper.

\section{References}

[1] WHO, Global Status Report on Noncommunicable Diseases 2010, World Health Organization, Geneva, Switzerland, 2011.

[2] N.-U. Neumann, M. Bellinger, and K. Frasch, "Gesundheitsförderung und Prävention: Mühsamer Weg zum richtigen Lebensstil," Deutsches Ärzteblatt, vol. 105, no. 51-52, pp. A2750A2752, 2008 .

[3] S. Abramson, J. Stein, M. Schaufele, E. Frates, and S. Rogan, "Personal exercise habits and counseling practices of primary care physicians: a national survey," Clinical Journal of Sport Medicine, vol. 10, no. 1, pp. 40-48, 2000.

[4] C. E. Lewis, C. Clancy, B. Leake, and J. S. Schwartz, "The counseling practices of internists," Annals of Internal Medicine, vol. 114, no. 1, pp. 54-58, 1991.

[5] E. Frank, "Physician health and patient care," Journal of the American Medical Association, vol. 291, no. 5, p. 637, 2004. 
[6] E. Frank, J. Breyan, and L. Elon, "Physician disclosure of healthy personal behaviors improves credibility and ability to motivate," Archives of Family Medicine, vol. 9, no. 3, pp. 287-290, 2000.

[7] L. Q. Rogers, B. Gutin, M. C. Humphries et al., "Evaluation of internal medicine residents as exercise role models and associations with self-reported counseling behavior, confidence, and perceived success," Teaching and Learning in Medicine, vol. 18, no. 3, pp. 215-221, 2006.

[8] J. Ma, G. G. Urizar Jr., T. Alehegn, and R. S. Stafford, "Diet and physical activity counseling during ambulatory care visits in the United States," Preventive Medicine, vol. 39, no. 4, pp. 815-822, 2004.

[9] J. Siegrist, R. Shackelton, C. Link, L. Marceau, O. von dem Knesebeck, and J. McKinlay, "Work stress of primary care physicians in the US, UK and German health care systems," Social Science and Medicine, vol. 71, no. 2, pp. 298-304, 2010.

[10] J. B. McKinlay and L. Marceau, "New wine in an old bottle: does alienation provide an explanation of the origins of physician discontent?" International Journal of Health Services, vol. 41, no. 2, pp. 301-335, 2011.

[11] I. van Ham, A. H. Verhoeven, K. H. Groenier, J. W. Groothoff, and J. De Haan, "Job satisfaction among general practitioners: a systematic literature review," European Journal of General Practice, vol. 12, no. 4, pp. 174-180, 2006.

[12] M. P. Leiter, E. Frank, and T. J. Matheson, "Demands, values, and burnout: relevance for physicians," Canadian Family Physician, vol. 55, no. 12, pp. e1224-e1226, 2009.

[13] Statistikamt Nord, Statistisches Jahrbuch Schleswig-Holstein 2010/2011, Statistikamt Nord, Kiel, Germany, 2011.

[14] M. Bullinger and I. Kirchberger, SF-36 Fragebogen Zum Gesundheitszustand, Hogrefe, Göttingen, Germany, 1998.

[15] B. M. Kudielka, D. Hanebuth, R. Von Känel, M. Gander, G. Grande, and J. E. Fischer, "Health-related quality of life measured by the SF12 in working populations: associations with psychosocial work characteristics," Journal of Occupational Health Psychology, vol. 10, no. 4, pp. 429-440, 2005.

[16] E. Frank and C. Segura, "Health practices of Canadian physicians," Canadian Family Physician, vol. 55, no. 8, pp. 810-811, 2009.

[17] G. B. Mensink, "Bundes-gesundheitssurvey: Körperliche aktivität," in Beiträge Zur Gesundheitsberichterstattung des Bundes, Robert Koch-Institut, Berlin, Germany, 2003.

[18] E. B. Oberg and E. Frank, "Physicians' health practices strongly influence patient health practices," Journal of the Royal College of Physicians of Edinburgh, vol. 39, no. 4, pp. 290-291, 2009.

[19] H. B. Jurkat, C. Vollmert, and C. Reimer, "Conflict experience of physicians in hospitals," Zeitschrift fur Psychosomatische Medizin und Psychotherapie, vol. 49, no. 3, pp. 213-231, 2003.

[20] RKI, "Daten und Fakten: Ergebnisse der Studie 'Gesundheit in Deutschland aktuell 2010"' in Beiträge Zur Gesundheitsberichterstattung des Bundes, Robert Koch-Institut, Berlin, Germany, 2012.

[21] G. B. Mensink, "Was essen wir heute? Ernährungsverhalten in Deutschland," in Beiträge Zur Gesundheitsberichterstattung des Bundes, Robert Koch-Institut, Berlin, Germany, 2002.

[22] U. Helmert and H. Strube, "The development of obesity in Germany in the period from 1985 until 2000," Gesundheitswesen, vol. 66, no. 7, pp. 409-415, 2004.

[23] S. Herpertz, "Obesity is more than an eating disorder-the multidimensional perspective of a pandemia," Zeitschrift fur Psychosomatische Medizin und Psychotherapie, vol. 54, no. 1, pp. 4-31, 2008.
[24] C. L. Ogden, M. D. Carroll, and K. M. Flegal, "Epidemiologic trends in overweight and obesity," Endocrinology and Metabolism Clinics of North America, vol. 32, no. 4, pp. 741-760, 2003.

[25] B. Buijsse, E. J. M. Feskens, M. B. Schulze et al., "Fruit and vegetable intakes and subsequent changes in body weight in European populations: results from the project on diet, obesity, and genes (DiOGenes)," American Journal of Clinical Nutrition, vol. 90, no. 1, pp. 202-209, 2009.

[26] J. W. Lampe, "Health effects of vegetables and fruit: assessing mechanisms of action in human experimental studies," American Journal of Clinical Nutrition, vol. 70, supplement 3, pp. 475S-490S, 1999.

[27] WHO, Global Recommendations on Physical Activity for Health, WHO Press, Geneva, Switzerland, 2010.

[28] D. E. Warburton, P. T. Katzmarzyk, R. E. Rhodes, and R. J. Shephard, "Evidence-informed physical activity guidelines for Canadian adults," Canadian Journal of Public Health, vol. 98, supplement 2, pp. S16-S68, 2007.

[29] H. Löllgen, A. Böckenhoff, and G. Knapp, "Physical activity and all-cause mortality: an updated meta-analysis with different intensity categories," International Journal of Sports Medicine, vol. 30, no. 3, pp. 213-224, 2009.

[30] G. B. M. Mensink, M. Thamm, and K. Haas, "Dietary intake in Germany 1998," Gesundheitswesen, vol. 61, no. 2, pp. S200-S206, 1999.

[31] T. Lampert, "Social determinants of tobacco consumption among adults in Germany," Bundesgesundheitsblatt-Gesundheitsforschung-Gesundheitsschutz, vol. 53, no. 2, pp. 108-116, 2010.

[32] D. E. Nelson, G. A. Giovino, S. L. Emont et al., "Trends in cigarette smoking among US physicians and nurses," Journal of the American Medical Association, vol. 271, no. 16, pp. 1273-1275, 1994.

[33] D. R. Smith and P. A. Leggat, "An international review of tobacco smoking in the medical profession: 1974-2004," BMC Public Health, vol. 7, no. 1, p. 115, 2007.

[34] E. Frank, D. J. Brogan, A. H. Mokdad, E. J. Simoes, H. S. Kahn, and R. S. Greenberg, "Health-related behaviors of women physicians vs other women in the United States," Archives of Internal Medicine, vol. 158, no. 4, pp. 342-348, 1998.

[35] P. Sebo, M. Bouvier Gallacchi, C. Goehring, B. Künzi, and P. A. Bovier, "Use of tobacco and alcohol by Swiss primary care physicians: a cross-sectional survey," BMC Public Health, vol. 7, p. 5, 2007.

[36] L. McCall, T. Maher, and L. Piterman, "Preventive health behaviour among general practitioners in Victoria," Australian Family Physician, vol. 28, no. 8, pp. 854-857, 1999.

[37] E. Frank, J. S. Carrera, L. Elon, and V. S. Hertzberg, "Basic demographics, health practices, and health Status of U.S. medical students," American Journal of Preventive Medicine, vol. 31, no. 6, pp. 499-505, 2006.

[38] E. Frank, J. Hedgecock, and L. K. Elon, "Personal health promotion at US medical schools: a quantitative study and qualitative description of deans' and students' perceptions," BMC Medical Education, vol. 4, no. 1, p. 29, 2004.

[39] A. J. Montgomery, C. Bradley, A. Rochfort, and E. Panagopoulou, "A review of self-medication in physicians and medical students," Occupational Medicine, vol. 61, no. 7, pp. 490-497, 2011.

[40] E. F. M. Adams, A. J. Lee, C. W. Pritchard, and R. J. E. White, "What stops us from healing the healers: a survey of help-seeking behaviour, stigmatisation and depression within 
the medical profession," International Journal of Social Psychiatry, vol. 56, no. 4, pp. 359-370, 2010.

[41] E. O. Rosvold and E. Bjertness, "Physicians who do not take sick leave: hazardous heroes?" Scandinavian Journal of Public Health, vol. 29, no. 1, pp. 71-75, 2001.

[42] M. Landry and C. Miller, "Presenteeism: are we hurting the patients we are trying to help?" Journal of General Internal Medicine, vol. 25, no. 11, pp. 1142-1143, 2010.

[43] A. B. Jena, D. C. Baldwin Jr., S. R. Daugherty, D. O. Meltzer, and V. M. Arora, "Presenteeism among resident physicians," Journal of the American Medical Association, vol. 304, no. 11, pp. 1166$1168,2010$.

[44] H. J. Hutt and S. Schmitt, "Impfstrategien-von WHO-Zielen zur praktischen Umsetzung," in Aspekte Der Prävention, W. Kirch, M. Middeke, and R. Rychlik, Eds., Thieme, Stuttgart, Germany, 2010.

[45] K. Leitmeyer, U. Buchholz, M. Kramer et al., "Influenza vaccination in German health care workers: effects and findings after two rounds of a nationwide awareness campaign," Vaccine, vol. 24, no. 47-48, pp. 7003-7008, 2006.

[46] L. F. Stead, G. Bergson, and T. Lancaster, "Physician advice for smoking cessation," Cochrane Database of Systematic Reviews, no. 2, p. CD000165, 2008.

[47] R. Y. Demers, A. V. Neale, R. Adams, C. Trembath, and S. C. Herman, "The impact of physicians' brief smoking cessation counseling: a MIRNET study," Journal of Family Practice, vol. 31, no. 6, pp. 625-629, 1990.

[48] A. V. Prokhorov, K. S. Hudmon, S. Marani et al., "Engaging physicians and pharmacists in providing smoking cessation counseling," Archives of Internal Medicine, vol. 170, no. 18, pp. 1640-1646, 2010.

[49] S. N. Bleich, O. Pickett-Blakely, and L. A. Cooper, "Physician practice patterns of obesity diagnosis and weight-related counseling," Patient Education and Counseling, vol. 82, no. 1, pp. 123129, 2011.

[50] B. Groß, S. Ulbricht, J. Rüge et al., "Förderung der Tabakabstinenz in der hausärztlichen Praxis: Die aktuelle Situation in Deutschland," Suchttherapie, vol. 8, no. 4, pp. 141-147, 2007.

[51] R. B. Bausell, "Health-seeking behaviors: public versus public health perspectives," Psychological Reports, vol. 58, no. 1, pp. 187190, 1986.

[52] V. Cokkinides, P. Bandi, C. McMahon, A. Jemal, T. Glynn, and E. Ward, "Tobacco control in the United States-recent progress and opportunities," CA Cancer Journal for Clinicians, vol. 59, no. 6, pp. 352-365, 2009.

[53] E. Gummersbach and H. H. Abholz, "Info-Flyer "Mammographie-Screening" in Deutschland-Welche Informationen enthält er und welche sollten enthalten sein?" Zeitschrift für Allgemeinmedizin, vol. 82, pp. 491-494, 2006.

[54] O. Olsen and P. C. Gøtzsche, "Cochrane review on screening for breast cancer with mammography," The Lancet, vol. 358, no. 9290, pp. 1340-1342, 2001.

[55] P. C. Gøtzsche and O. Olsen, "Is screening for breast cancer with mammography justifiable?” The Lancet, vol. 355, no. 9198, pp. 129-134, 2000.

[56] C. Biesheuvel, S. Weige, and W. Heindel, "Mammography screening: evidence, history and current practice in Germany and other European countries," Breast Care, vol. 6, no. 2, pp. 104-109, 2011.

[57] E. Frank and L. K. Harvey, "Prevention advice rates of women and men physicians," Archives of Family Medicine, vol. 5, no. 4, pp. 215-219, 1996.
[58] E. Frank, C. Segura, H. Shen, and E. Oberg, "Predictors of Canadian physicians' prevention counseling practices," Canadian Journal of Public Health, vol. 101, no. 5, pp. 390-395, 2010.

[59] D. L. Roter, J. A. Hall, and Y. Aoki, "Physician gender effects in medical communication: a meta-analytic review," Journal of the American Medical Association, vol. 288, no. 6, pp. 756-764, 2002.

[60] K. D. Bertakis, "The influence of gender on the doctor-patient interaction," Patient Education and Counseling, vol. 76, no. 3, pp. 356-360, 2009.

[61] E. Frank, R. Rothenberg, C. Lewis, and B. F. Belodoff, "Correlates of physicians' prevention-related practices: findings from the Women Physicians' Health Study," Archives of Family Medicine, vol. 9, no. 4, pp. 359-367, 2000.

[62] B. Bestmann, V. Rohde, A. Wellmann, and T. Küchler, "Berufsreport 2003 Zufriedenheit von Ärztinnen und Ärzten," Deutsches Ärzteblatt, vol. 101, no. 1-2, pp. A28-A23, 2004. 


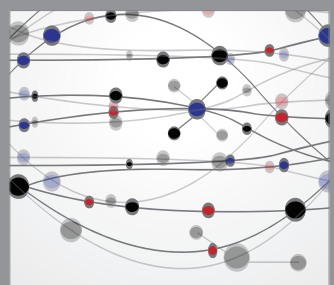

The Scientific World Journal
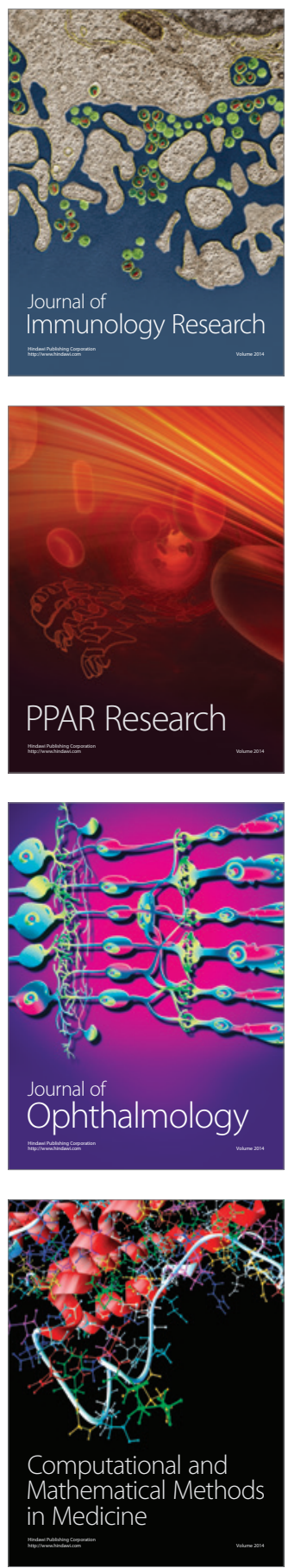

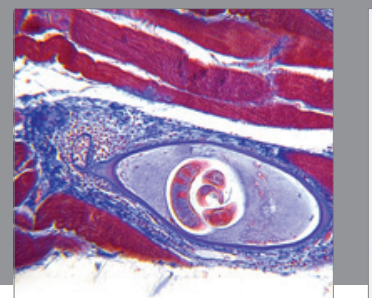

Gastroenterology

Research and Practice
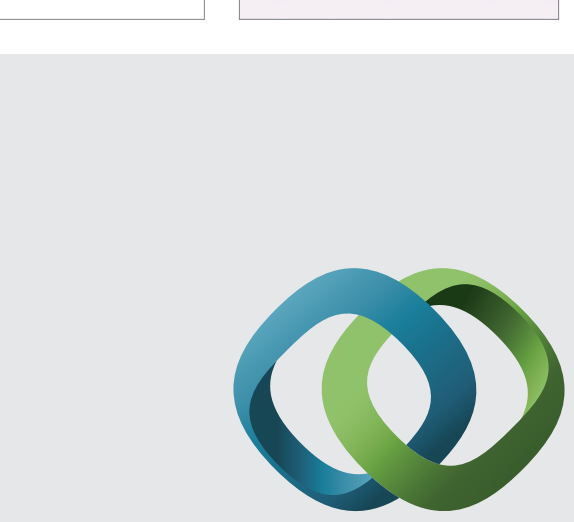

\section{Hindawi}

Submit your manuscripts at

http://www.hindawi.com
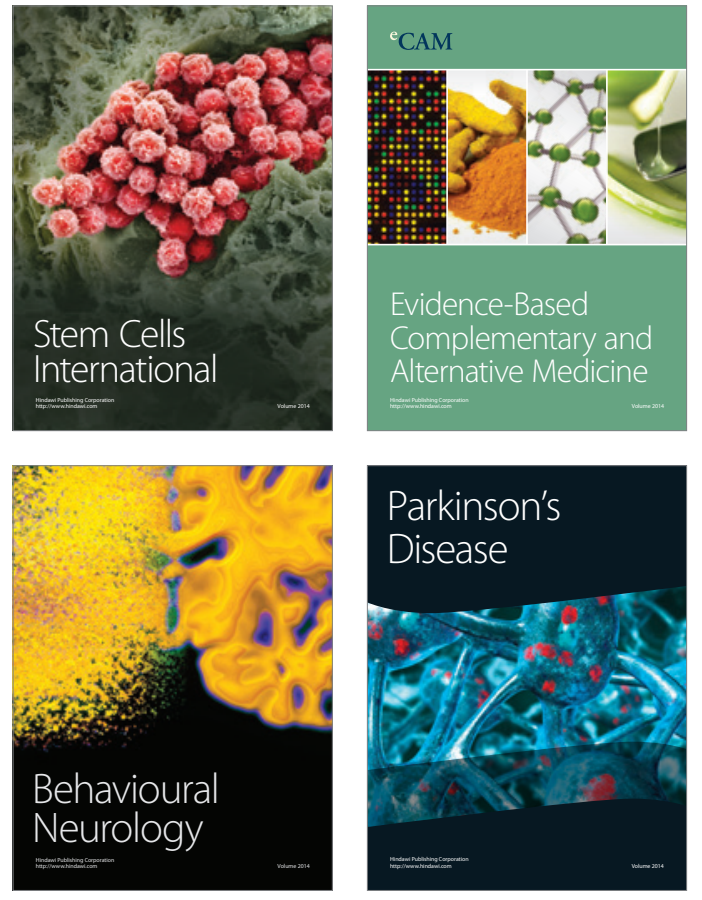
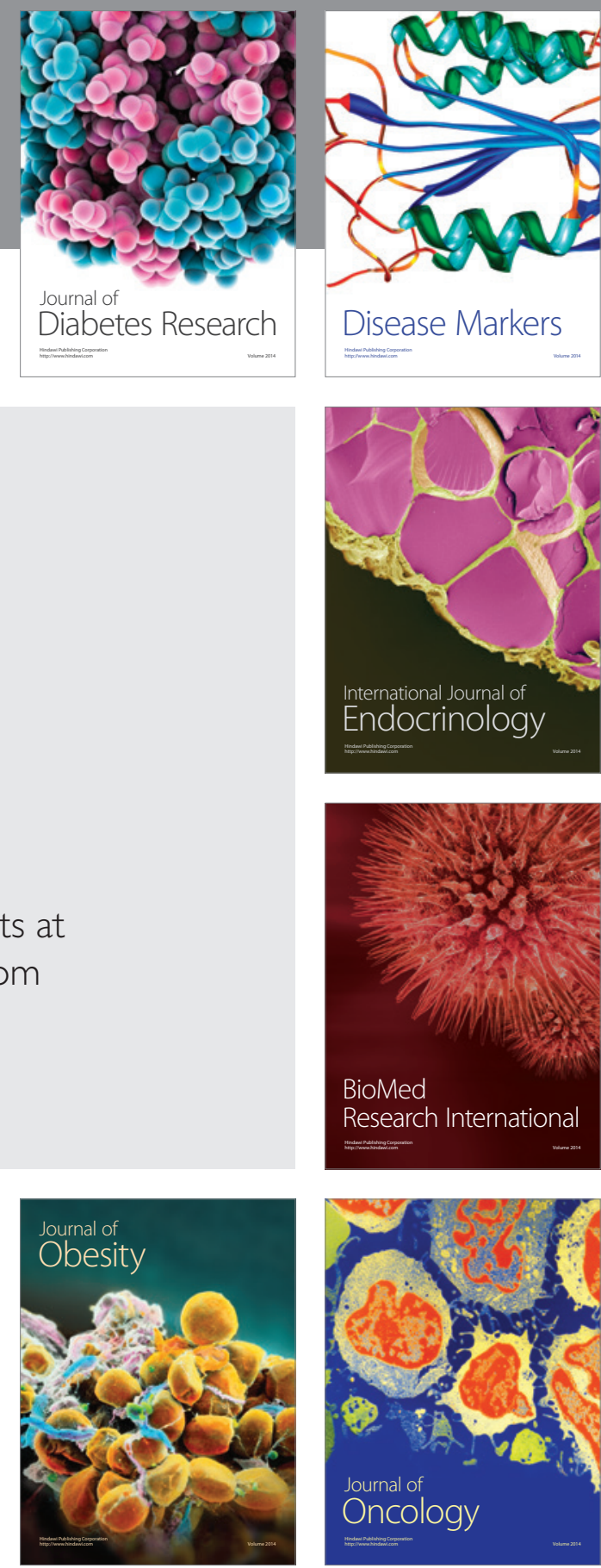

Disease Markers
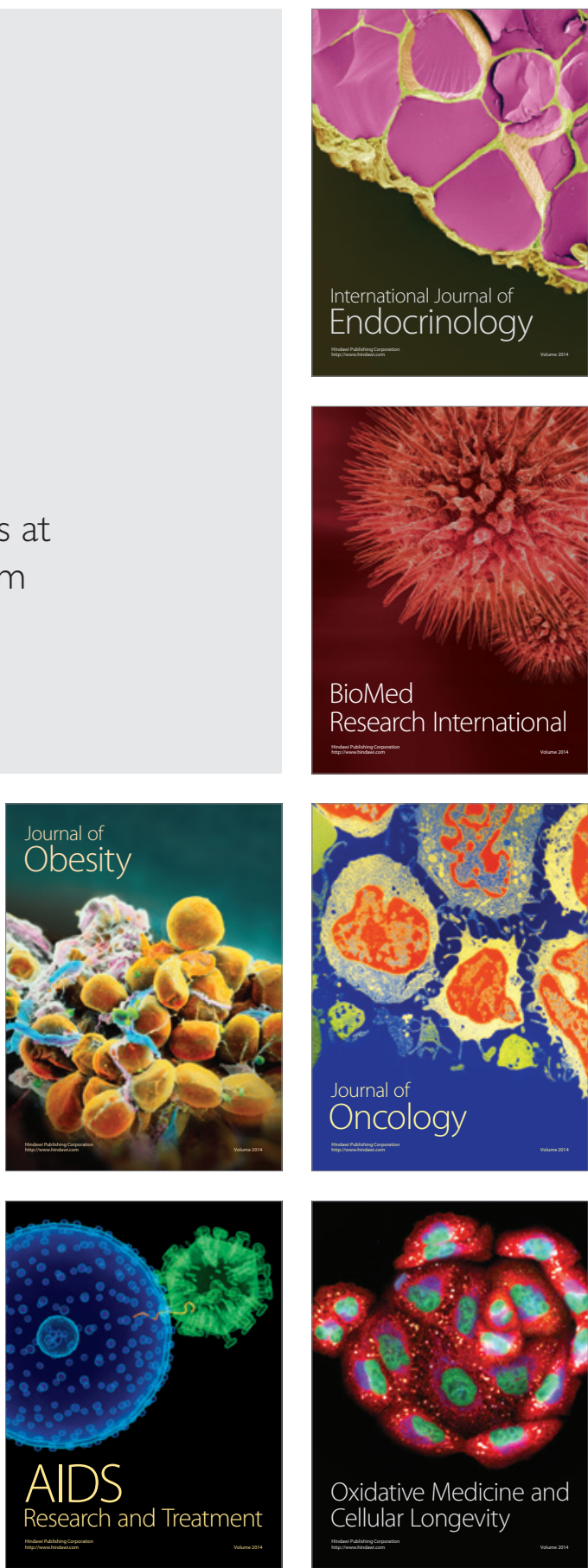